\title{
Volatile Composition and Antioxidant Properties of Clove Products
}

\author{
Elvira M Gaspar ${ }^{1 *}$, Renato Duarte ${ }^{1,2}$ and José C Santana ${ }^{1}$ \\ ${ }^{1}$ Department of Chemistry, Faculty of Sciences and Technology, Universidade NOVA de Lisboa, Quinta da Torre, Portugal \\ ${ }^{2} I P E N-C N E N / S P$, Nuclear and Energy Research Institute, University São Paulo Av, Brazil
}

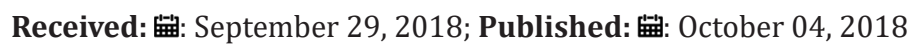

*Corresponding author: Elvira M Gaspar, LAQV-REQUIMTE, Department of Chemistry, Faculty of Science and Technology, Universidade NOVA de Lisboa, Quinta da Torre, 2825-114 Caparica, Portugal

\begin{abstract}
The volatile chemical composition and antioxidant properties of whole and ground clove buds have been revisited together with those from essential oils. The major bioactive compounds showed to be eugenol, eugenyl acetate and $\beta$-caryophyllene; their different quantitative contribution justifies the unequal aroma and antioxidant properties of clove products. Eugenol was identified as the most abundant chemical from whole clove buds and essential oils, while $\beta$-caryophyllene is the dominant compound of ground clove, the preferred product in the food industry. This research enables the clarification of the role of clove products in culinary, food industry and in dieting respecting chemical composition and properties.
\end{abstract}

Keywords: Antioxidants; $\beta$-Caryophyllene; Clove Buds; Eugenol; Syzygium Aromaticum

\section{Introduction}

The actual lifestyle including processed foods, reliance on medications and high exposure to chemicals or environmental pollutants exposes humans to high rates of oxidative stress from a young age. When antioxidant levels in the human body are lower than that of free radicals due to many different causes including poor nutrition and toxin exposure, oxidation wreaks havoc in the body. Then, an accelerated aging, damaging or mutation of cells, activation of harmful genes within DNA and an overloading immune system can occur. So, this is the reason why nowadays people take and use antioxidants which are chemical substances that inhibit oxidation and are especially used to counteract the deterioration of stored food products or removes potentially damaging oxidizing agents in a living organism [1]. For example, natural antioxidant compounds have been shown to be useful in attenuating the extent of hypercholesterolemia as they correct the imbalance between free radicals (pro-oxidants) resulting from increased cholesterol level and anti-free radicals (antioxidants) [2].

Eating is yet the simplest and optimal delivery system available for bioactive molecules. Eating habits have become more adventurous with consumers turning more and more to ethnic cuisine and spicy foods. The ethnic food trend is reflected in higher consumption of spices. Spices are vegetable products used to provide flavoring, seasoning, and aroma to foods [3]. They are commonly used to enhance the taste or aroma of food and some of them have been described as strong antioxidants, having other beneficial qualities, too. Spices used to have an important social role due to their ability to heal and perpetuate life, through their use as medicines and in dieting. Spices are able to enrich or alter the quality of food, for instance, changing the taste to give it zest or pungency, a piquant or lasting flavoring, or a relish [4]. The role of spices is related to the bioactivity of their constituents, namely the antioxidant activity [5-7]. Clove, the dried aromatic flower bud of the evergreen trees, Eugenia caryophyllata (=Syzygium aromaticum) (Myrtaceae) has been used in the food industry and domestic culinary purposes as a flavoring agent due to their intense flavor and also to the medicinal attributes and antioxidant activity $[4,8]$.

The main products of clove are: whole or ground clove buds, essential oils (produced from clove buds, stem and leaf) and oleoresins. Ground clove is produced by milling or grinding of the dried clove buds. Industrially, the procedure is conducted at low temperature $\left(25^{\circ}-35^{\circ} \mathrm{C}\right)$ to prevent the loss of valuable volatile chemical constituents during processing. The powder may have several degrees of fineness, depending on the ultimate application and the country. In the food industry clove is often used in the form of ground, in a small amount due to intense aroma. Clove's antioxidant properties are responsible for being capable of neutralize free radicals associated with cancer. According to the literature, the antioxidant power varies depending on the type of 
clove product. The antioxidant activity of ground clove in meat lipids showed to be concentration dependent [9]. Clove showed to be most effective than sage and rosemary, being ginger and thyme the weakest. Eugenol has been identified as the major volatile chemical component in clove $[4,10]$. The eugenol content $(\%)$ was described as the key parameter for quality and purity control of marketed clove buds [11].

The major constituent of clove oil is eugenol, to which are attributed many of the antioxidant properties [12]. The antioxidant activity may occur via various mechanisms such as scavenging the radicals and chelating metal ions. Eugenol reportedly participates in photochemical reactions [13] and displays strong antioxidant activity [12]. Jirovetz et al. [14] found that the antioxidant action of $0.005 \%$ clove oil was identical to that of standard butylated hydroxytoluene at a concentration of $0.01 \%$. However, it was already described that iso-eugenol, also present in clove products and more rarely found in nature, exhibits higher antioxidative efficiency than eugenol [15]. $\beta$-caryophyllene is a volatile compound also found as an important component of clove oil. It also has appreciable antioxidant activity and has recently been tested in diseases associated with inflammation and oxidative stress. Its antioxidant activity leaded to reduction of reactive oxygen species (ROS) due to its free-radical scavenging effect against hydroxyl anions, superoxide anions and lipid peroxides [2]. $\beta$-caryophyllene created an interest as a lead for drug development [2]. In this study, the volatile composition of whole and ground clove buds and their essential oils have been revisited and compared. The knowledge of volatile compositions clarifies their use and antioxidant properties. Headspace solid phase micro-extraction gas chromatography time of flight mass spectrometry (HS-SPME-GC-TOF-MS) was used as analytical technique. As far as we know, the volatile composition of different products of clove has not been compared yet.

\section{Methods}

\section{a. Materials}

Hexane was purchased from Sigma-Aldrich (Steinheim, Germany), analytical reagent grade. Deionised and purified water (Millipore unit, USA) was used. Working standards of eugenol (> 98.0\%), $\beta$-caryophyllene (> 80\%) and eugenyl acetate (> 98\%) were purchased from Tokyo Kasei (Nihonbashi, Tokyo, Japan); $\alpha$-caryophyllene ( $\alpha$-humulene) $(\geq 96.0 \%)$ were purchased from Sigma-Aldrich (Steinheim, Germany) and $\alpha$-copaene (> 98\%) was purchased from Santa Cruz Biotechnology (California, USA) Flower buds of the evergreen trees, Eugenia caryophyllata Thunb. (=Syzygium aromaticum (L.) Merr. \& L.M. Perry) (Myrtaceae) from Brazil were donated by IPEN-CNEN/SP, University São Paulo, Brazil. Clove buds from India were purchased in an ethnic supermarket in Lisbon, Portugal.

\section{b. Instruments and equipment}

The separations were performed using a fused silica capillary column: SLB-5ms (Supelco, Bellefonte), $60 \mathrm{~m} \times 0.25 \mathrm{~mm}$ I.D., film thickness $0.25 \mu \mathrm{m}$. Oven temperature was programmed from $35 \circ \mathrm{C}$, hold $5 \mathrm{~min}$, to $240 \circ \mathrm{C}$ at $4 \circ \mathrm{Cmin}-1$, hold $10 \mathrm{~min}$. Helium was used as carrier gas at the flow rate of $1.0 \mathrm{mLmin}-1$. High resolution gas chromatography-mass spectrometry (HRGC-MS) measurements were performed using an Agilent 6850 chromatograph coupled with 5975C MSD with triple-axis detector: mode EI+, 70eV, source temperature $225 \circ \mathrm{C}$, interface temperature $280 \circ \mathrm{C}$. Full scan mode was used in the range of $40-450 \mathrm{amu}$, at a rate of 10 scans -1 . The injector was used in the split mode; the injector temperature was set at $270^{\circ} \mathrm{C}$. HRGC-TOF-MS measurements were performed under identical chromatographic conditions, using an Agilent 6890 (Santa Clara, CA, USA) coupled with a Micromass model GCT equipment (TOF resolution 7000): mode $\mathrm{EI}+, 70 \mathrm{eV}$, source temperature $250 \circ \mathrm{C}$, interface temperature $225{ }^{\circ} \mathrm{C}$. Full scan mode was used in the range of $40-400 \mathrm{amu}$, at a rate of 0.9 scans- 1 .

\section{c. Experimental \\ i. Sample preparation}

\section{A. Headspace solid phase micro-extraction (HS-SPME)}

Four (4) different types of solid phase microextraction (SPME) fibers were tested in this work for the extraction of volatiles: 100 $\mu \mathrm{m}$ polydimethylsiloxane (PDMS) and $85 \mu \mathrm{m}$ polyacrylate (PA) as absorbent type fibers, and $75 \mu \mathrm{m}$ carboxen/polydimethylsiloxane (CAR/PDMS) and 50/30 $\mu \mathrm{m}$ divinylbezene/carboxen/polydimethylsiloxane (DVB/CAR/PDMS) as adsorbent type fibers [16-18]. All of them were purchased from Supelco (Bellefonte, PA, USA). Absorbent type fibers extract by the partitioning of analytes into a "liquid-like" phase. The polarity of the fiber coating controls the attraction of the volatiles to that particular coating, but it's the thickness of the fiber that retains the analytes. There is virtually no competition between analytes. The analytes migrate in and out of the coating [18]. On the other hand, theoretically, adsorbent type fibers extract volatiles by physically interacting with the compounds. The extraction can be accomplished by trapping the analytes in internal pores. Because there are a limited number of sites, the analytes can compete.

This can result in reduced capacity and/or displacement of analytes with low distribution constants by those with higher distribution constants [18]. Fibers were initially conditioned according to the manufacturer's instructions: each one was inserted into a GC-FID injector during $1 \mathrm{~h}$ at $270^{\circ} \mathrm{C}$, in order to remove contaminants and to stabilize the polymeric phase before use. To avoid any background problem, this SPME preprocessing step was applied in all experiments. Samples (1g of whole buds or $1 \mathrm{~g}$ of ground clove) were placed into $50 \mathrm{~mL}$ EPA (chemically inert clear type I borosilicate glass) vials capped with a PTFEfaced silicone septum. After $1 \mathrm{~h}$, the holder needle was inserted through the septum and SPME fibers were exposed to the sample's headspace (HS-SPME). Each sample was extracted for $30 \mathrm{~min}$ (time to reach the partitioning equilibrium between the sample matrix and the extraction phase) at room temperature. In this case, convection conditions do not affect the amount extracted [16,17]. After extraction, each fiber was withdrawn into the holder needle, removed from the vial, and introduced immediately into the GCTOF-MS injector port for $15 \mathrm{~min}$ at $270^{\circ} \mathrm{C}$ for thermal desorption of the analytes. Between sampling and sample extraction, a blank was run to avoid carry over processes. 
B. Essential oils: One hundred and fifty gram (150g) of whole buds and ground clove were (separately) hydrodistilled with $300 \mathrm{~mL}$ of water for $3 \mathrm{~h}$ using an all-glass Clevenger apparatus (Figure S1, supplementary material) [19]. It was heated at $100^{\circ} \mathrm{C}$ by heating mantle; the essential oils were collected, dried over anhydrous sodium sulphate and stored at $-32^{\circ} \mathrm{C}$ until they were analyzed.

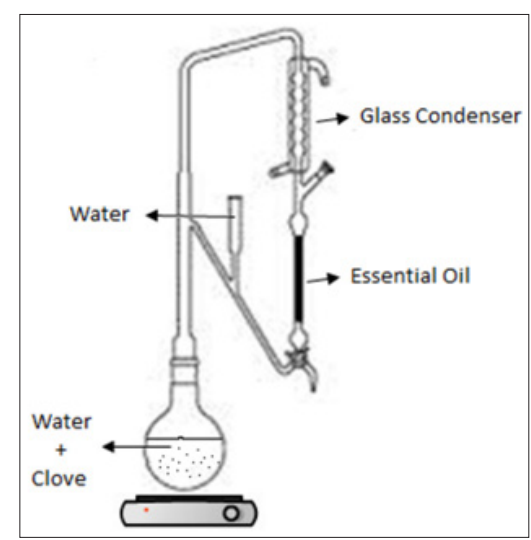

Figure S1- Clevenger hydro distillation apparatus.
C. Quantification: The standard addition method was used in this work. The solutions of target aroma standards at five different levels of concentration were added to the samples prior to the HS analyses. Quantitative analysis was finished by the calibration curve acquired.

\section{Results and Discussion}

The volatile compositions of different clove products were compared in order to understand how they impart aroma and also antioxidant properties to foods.

\section{a. Sample Preparation}

The main purpose of any sample preparation methodology is to transfer compounds from the matrix to be studied into a suitable form that is cleaned-up, concentrated, and compatible with the analytical system [20]. As far as the selection of SPME fiber concerns, the chemical nature of compounds influences fiber selection. Taking into account the chromatograms obtained with standard solutions and the chemical nature of target compounds (Table S1, supplementary material), the triple fiber (DVB/CAR/ PDMS) was selected for SPME analysis (Figure S2, supplementary material) (Table 1).

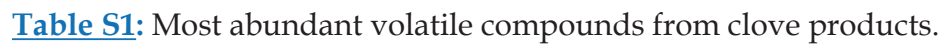

\begin{tabular}{|c|c|c|c|c|}
\hline Compounds & Structure & $\begin{array}{l}\text { Boiling point } \\
\left({ }^{\circ} \mathrm{C}\right) 760 \mathrm{mmHg}\end{array}$ & $\begin{array}{c}\text { Retention timea) } \\
\operatorname{tr}(\mathrm{min})\end{array}$ & CAS \\
\hline $\begin{array}{c}\text { Eugenol } \\
\text { (1) }\end{array}$ & & $254-255$ & 37.5 & CAS 97-53-0 \\
\hline $\begin{array}{c}\beta \text {-Caryophyllene } \\
\text { (2) }\end{array}$ & & $\begin{array}{l}245.3^{\mathrm{b})} \\
268.39^{\mathrm{c})}\end{array}$ & 40 & CAS 87-44-5 \\
\hline $\begin{array}{c}\text { Eugenyl acetate } \\
\text { (3) }\end{array}$ & & $281-286$ & 42.6 & CAS 93-28-7 \\
\hline $\begin{array}{c}\alpha \text {-Caryophyllene } \\
\text { ( } \alpha \text {-humulene) } \\
(4)\end{array}$ & & $166-168$ & 41.2 & CAS 6753-98-6 \\
\hline$\alpha$-Copaene (5) & & 248.5 & 38.5 & CAS 3856-25-5 \\
\hline
\end{tabular}

Note: a)GC-MS analysis. Chromatographic conditions reported in experimental section.

b)http:/ / www.chemnet.com/dict/dict--87-44-5--en.html

c)http:/ / www.lookchem.com/Caryophyllene/;http://www.chemspider.com/Chemical-Structure.4444848.html 


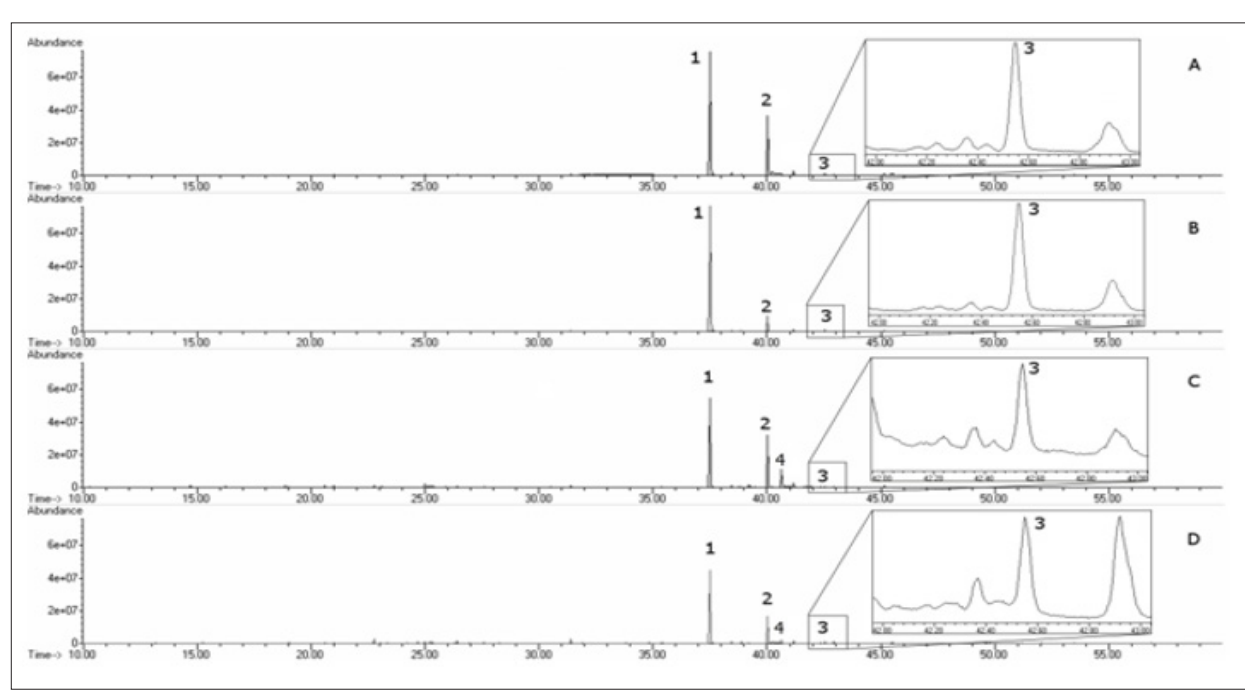

Figure S2- Headspace composition of whole clove buds sampled by SPME using four fibers: PDMS (A), PA (B), CAR/ PDMS (C) and DVB/CAR/PDMS (D). Compounds: eugenol (1), $\beta$-caryophillene (2), eugenyl acetate (3), a-caryophyllene (4). Chromatographic conditions described in Experimental.

Table 1: Volatile composition of clove products.

\begin{tabular}{|c|c|c|c|c|}
\hline \multicolumn{5}{|c|}{$\begin{array}{c}\text { Compounds } \\
\text { (\%/Peak Area)* }\end{array}$} \\
\hline Matrix & Sample preparation & $\begin{array}{c}\text { Eugenol } \\
\text { (1) }\end{array}$ & $\begin{array}{c}\beta \text {-Caryophyllene } \\
\text { (2) }\end{array}$ & $\begin{array}{c}\text { Eugenyl acetate } \\
\text { (3) }\end{array}$ \\
\hline \multirow{2}{*}{$\begin{array}{l}\text { Whole } \\
\text { clove } \\
\text { buds }\end{array}$} & HS-SPME & $59.25 / 1.40 \times 10^{9}$ & $18.75 / 4.43 \times 10^{8}$ & $0.69 / 1.63 \times 10^{7}$ \\
\hline & Essential oil & $89.65 / 2.42 \times 1010$ & $1.04 / 2.81 \times 108$ & $8.03 / 2.17 \times 109$ \\
\hline \multirow{2}{*}{$\begin{array}{l}\text { Ground clove } \\
\text { buds }\end{array}$} & HS-SPME & $31.60 / 2.48 \times 10^{9}$ & $57.26 / 4.49 \times 10^{9}$ & $1.32 / 1.03 \times 10^{8}$ \\
\hline & Essential oil & $84.97 / 2.38 \times 10^{10}$ & $6.50 / 1.82 \times 10^{9}$ & $5.91 / 1.65 \times 10^{9}$ \\
\hline
\end{tabular}

Note: *Concentration (\%) based on peak area integration.

\section{b. Volatile Composition of Whole Clove:}

The headspace composition of whole clove showed as major volatiles: eugenol (1), $\beta$-caryophillene (2), eugenyl acetate (3), $\alpha$-caryophyllene (4), $\alpha$-copaene (5). Eugenol was identified as the most abundant volatile ( $63.94 \%$ conc), being $\beta$-caryophyllene the second more abundant component (33.97\% conc). This result is in good agreement with literature data $[3,11,12,14,21]$.

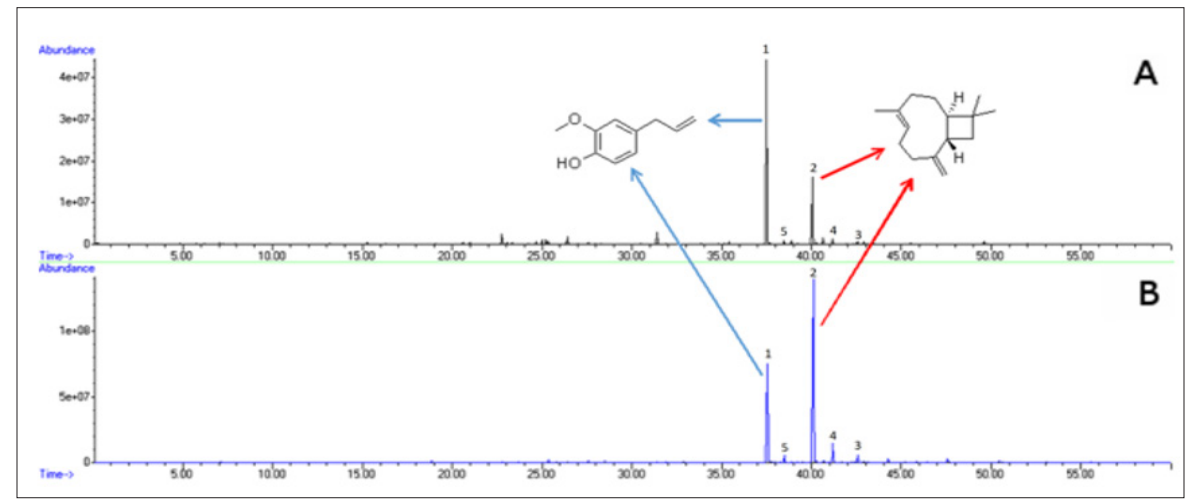

Figure 1: Chromatographic profiles of aroma composition of whole (A) and ground (B) clove from Brazil. Analytical conditions are in Experimental. 


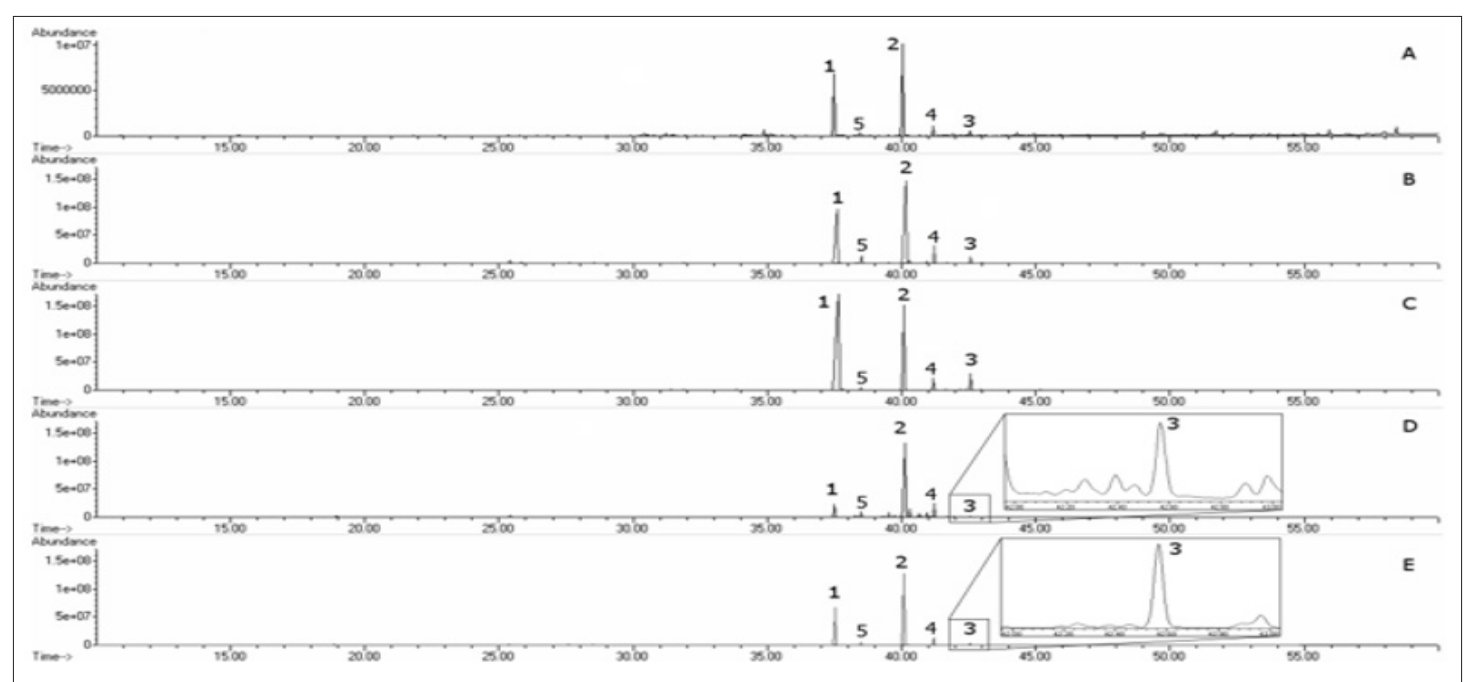

Figure S3- Volatile composition of ground clove sampled differently: SHS (A), HS-SPME-(PDMS) (B), HS-SPME-(PA) (C), HS-SPME-(CAR/PDMS) (D) and HS-SPME-(DVB/CAR/PDMS) (E). Compounds: eugenol (1), $\beta$-caryophillene (2), eugenyl acetate (3), a-caryophyllene (4), a-copaene (5). Chromatographic conditions described in Experimental.

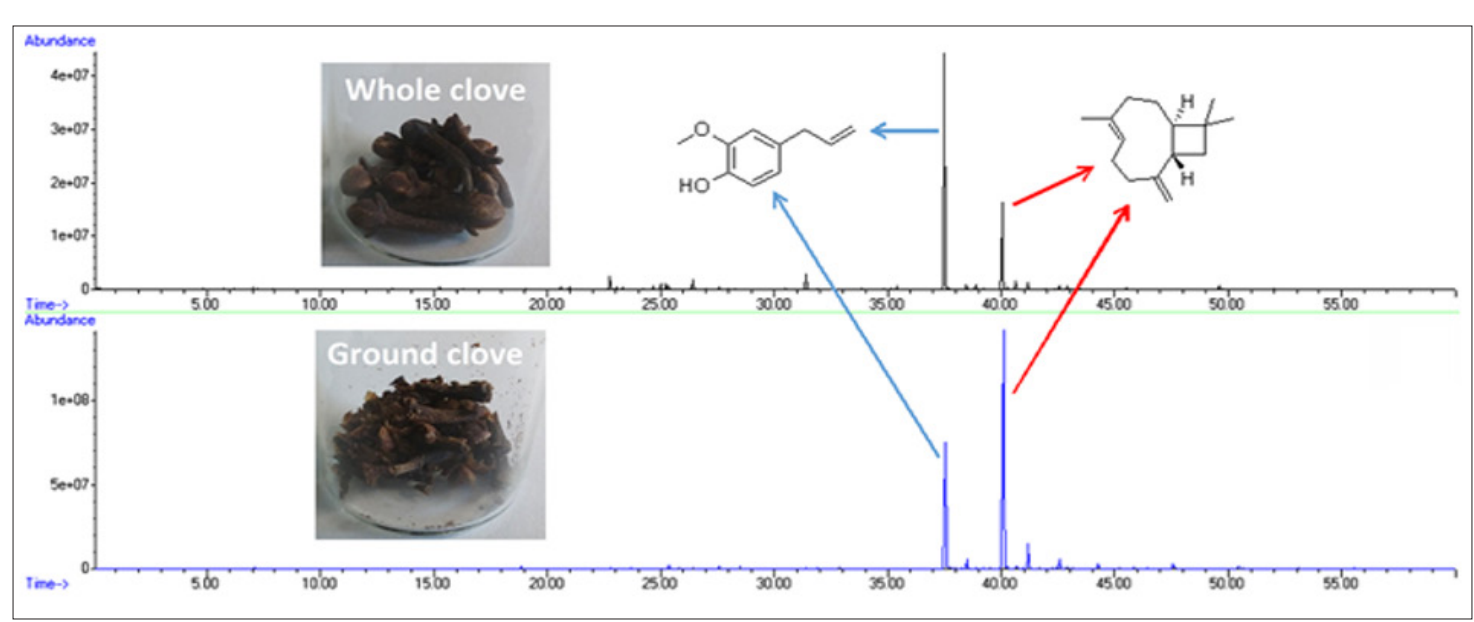

Figure S4- Graphical Abstract.

\section{c. Volatile Composition of Ground Clove}

Ground clove has been the predominant industry choice as a flavoring agent added to food and it has been commercialized as an independent food product, too. So, in this study clove buds were grounded to powder and its aroma was analyzed (Figures S3 \& S4, supplementary material). Surprisingly, the volatile (headspace) composition of ground clove showed a different pattern when compared with the volatile profile from whole buds. $\beta$-caryophyllene proved to be the most abundant chemical (49.31\% conc). The comparison between compositions from whole and ground clove (Figure 1) demonstrated this unexpected result: $\beta$-caryophyllene is the most abundant volatile of ground clove while eugenol is the dominant compound of whole clove buds.

This unexpected difference between eugenol and $\beta$-caryophyllene contents corresponds to different aromas of the two clove-derived products. Because smell is closely connected to taste, using whole or ground clove as food flavoring agents is not the same. Factually, whole clove and ground clove are two different flavoring agents. The world-recognized (high) antioxidant power of clove, responsible for preservation of lipids and reduction of lipid peroxidation in food (and other biological systems), has been attributed to eugenol $[12,21]$.

However, $\beta$-Caryophyllene is the major volatile of ground clove and it has also appreciable antioxidant activity and has been used in diseases associated with oxidative stress [2]. In order to verify if this result is related to the geographic origin of clove, we decided to study another clove commercialized in Portugal. Figure 2 illustrates the aroma's composition of clove from India. As can be seen, a good agreement between the volatile compositions of clove from India and from Brazil was obtained and $\beta$-caryophyllene proved to be the major volatile of ground clove from both origins. Ninety five percent $(95 \%)$ of food's flavor is known to be determined by 
the aroma detected by the olfactory epithelium in the nose. Since chemical reactions take place while eating, the unequal aromas of ground and whole clove are also responsible for different tastes due to different activation of neurons.

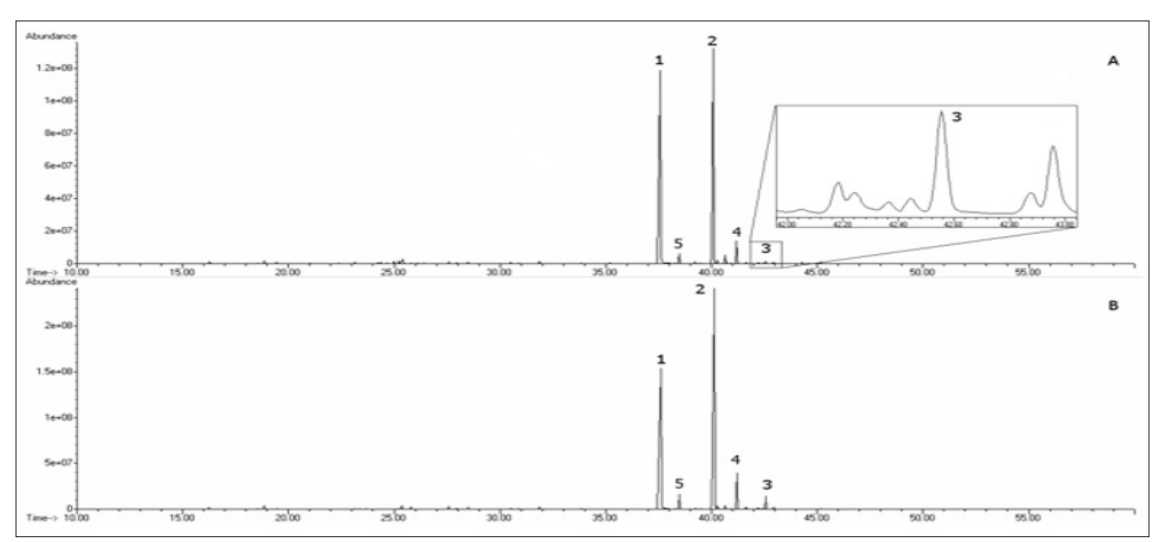

Figure 2: Aroma profiles of whole (A) and ground (B) clove from India. Compounds: eugenol (1), $\beta$-caryophillene (2), eugenyl acetate (3), a-caryophyllene (4), a-copaene (5). Analytical conditions described in Experimental.

\section{d. Study of Essential Oils}

To better understand the aroma of all clove-derived products, we decided to do comparative headspace analyses of the essential oils. Figure 3 demonstrates that eugenol is the dominant volatile constituent from essential oils of both whole and ground clove.

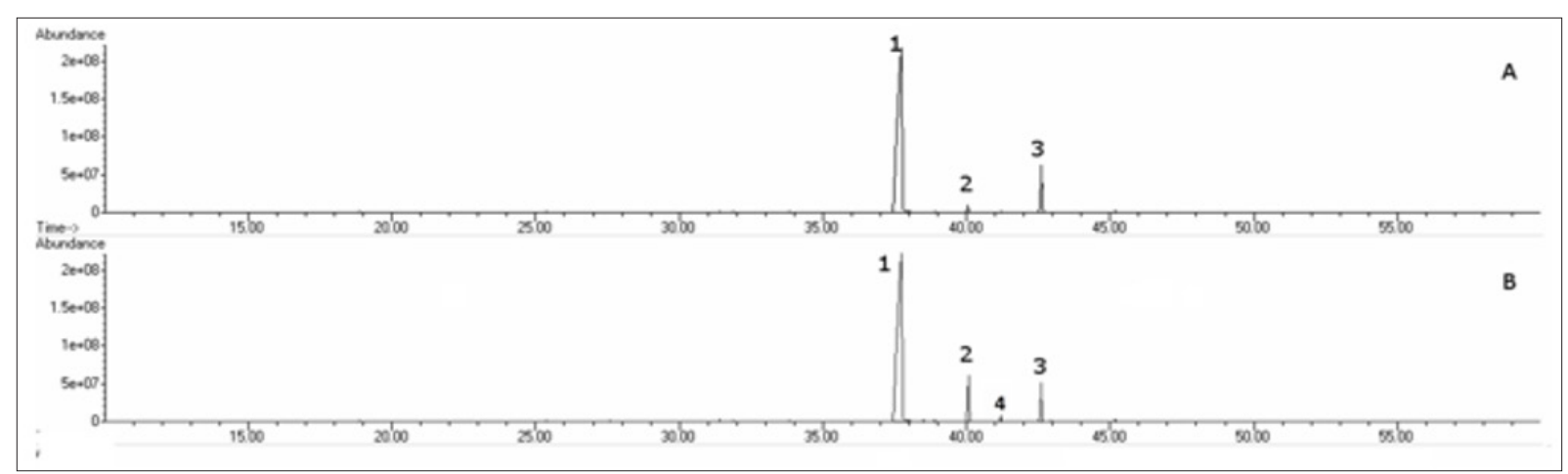

Figure 3: Comparison of essential oils of whole (A) and ground (B) clove buds. Compounds: eugenol (1), $\beta$-caryophillene (2), eugenyl acetate (3), a-caryophyllene (4). Analytical conditions described in Experimental.

\section{Conclusion}

The list of flavorings and source materials was established by the Commission Implementing Regulation (EC) No 872/2012. As a spice, clove is valuable in adding flavor to foods. This comparative research demonstrated that the aroma composition depends on the clove product. Eugenol proved to be the main volatile of whole clove buds while $\beta$-caryophyllene is the dominant compound in the aroma from ground clove. The knowledge of volatile compositions of whole and ground clove clarifies its different use in culinary, providing the opportunity to adapt recipes. Eugenol and $\beta$-caryophyllene have different aroma and exhibit also different antioxidant properties. To the best of our knowledge, this is the first comparative chemical study involving the aroma of different clove products.

\section{Acknowledgements}

The authors acknowledge financial support from Conselho Nacional de Desenvolvimento Científico e Tecnológico - Brazil
(CNPq) (Renato Duarte - 201998/2011-9) and Fundação para a Ciência e Tecnologia - Portugal (FCT) (José Santana - SFRH/ BNDE/51585/2011).

\section{References}

1. Singh G, Marimuthu P, De HeluaniI CS, Catalan CA N (2006) Antioxidant and Biocidal Activities of Carum nigrum (Seed) Essential Oil, Oleoresin, and Their Selected Components. J Agric Food Chem 54(1): 174-181.

2. Harb AA, Bustanji YK, Abdalla SS (2018) Hypocholesterolemic effect of $\beta$-caryophyllene in rats fed cholesterol and fat enriched diet. J Clin Biochem Nutr 62(3): 230-237.

3. Peter KV (2012) Introduction. Handbook of Herbs and Spices KV Peter (Eds.) 1st ed Cambridge, England: Woodhead Publishing Limited p. 1-12.

4. Nurdjannah N, Bermawie N Clove (2001) In: Peter KV (Eds.) Handbook of herbs and spices. Woodhead Publishing Series in Food Science, Technology and Nutrition. Cambridge: Woodhead Publishing Limited pp. 281-304.

5. Charles DJ (2013) Antioxidant properties of spices, herbs and other sources. New York: Springer, USA. 
6. Shobana S, Naidu KA (2000) Antioxidant activity of selected Indian spices. Prostaglandins Leukot Essent Fatty Acids 62: 107-110.

7. Madsen HL, Bertelsen G (1995) Spices as antioxidants. Trends Food Sci Technol 6: 271-277.

8. Kamatou GP, Vermaak I, Viljoen AM (2012) Eugenol from the remote Maluku islands to the international market place: a review of a remarkable and versatile molecule. Molecules 17: 6953-6981.

9. Shahidi F, Pegg BP, Saleemi ZO (1995) Stabilization of meat lipids with ground spices. Journal of Food Lipids 2(3): 145-153.

10. Jung M, Shin Y, Oh S, Kim N, Dong Sun Lee (2006) Headspace Hanging Drop Liquid Phase Microextraction and Gas Chromatography-Mass Spectrometry for the analysis of flavors from clove buds. Bull Korean Chem Soc 27: 231-236.

11. Ramlingam P, Ramakanth Reddy D, Harish Kumar Raju C, Sai Ram Reddy P, Vamshi Krishna PV (2012) Quality control of marketed clove buds - reference to their quality and purity as per WHO guidelines. Int J Bioassays 01: 1-7.

12. Ogata M, Hoshi M, Urano S, Endo T (2000) Antioxidant activity of eugenol and related monomeric and dimeric compounds. Chem Pharm Bull 48(10): 1467-1469.

13. Mihara S, Shibamoto T (1982) Photochemical reactions of eugenol and related compounds: synthesis of new flavor chemicals. J Agric Food Chem 30 (6): 1215-1218

ISSN: 2574-1241

DOI: 10.26717/BJSTR.2018.09.001831

Elvira M Gaspar. Biomed J Sci \& Tech Res

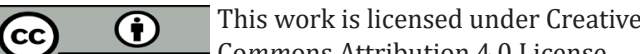
Commons Attribution 4.0 License

Submission Link: https://biomedres.us/submit-manuscript.php
14. Jirovetz L, Buchbauer G, Stoilova I, Stoyanova A, Krastanov A, et al. (2006) Chemical Composition and Antioxidant Properties of Clove Leaf Essential Oil. J Agric Food Chem 54 (17): 6303-6307.

15. Ivanov SA, Davcheva YG (1992) Antioxidative effects of eugenol and isoeugenol. Oxidation Commun15:200-203.

16. Pawliszyn J (2000) Theory of Solid-Phase Microextraction. J Chromatogr Sci 38(7): 270-278.

17. Vas G, Vékey K (2004) Solid-phase microextraction: a powerful sample preparation tool prior to mass spectrometric analysis. J Mass Spectrom 39: 233-254.

18. Shirey RE, Mindrup RF (2018) SPME - adsorption versus absorption: which fiber is best for your application? Supelco.

19. Clevenger JF (1928) Apparatus for the determination of volatile oil. J Am Pharm Assoc 17: 345-349.

20. Ulrich S (2000) Solid phase microextraction in biomedical analysis. J Chromatogr A 902: 167-194.

21. Chaieb K, Hajlaoui H, Zmantar T, Kahla Nakbi AB, Rouabhia M, et al. (2007) The Chemical Composition and Biological Activity of Clove Essential Oil, Eugenia caryophyllata (Syzigium aromaticum L. Myrtaceae): A Short Review. Phytother Res 21(6): 501-506. 